\title{
How to enhance awareness on bullying for Special Needs Students using "Edpuzzle" a web 2.0 tool
}

\author{
Sara Abou Afach, Elias Kiwan, Charbel Semaan ${ }^{1}$
}

\begin{tabular}{l} 
ARTICLE INFO \\
\hline Article History: \\
Received 12.07.2017 \\
Received in revised form \\
17.09.2017 \\
Accepted \\
Available online 01.01 .2018
\end{tabular}

\begin{abstract}
The purpose for this study is to be able to deliver messages and life tips for special needs students in an easy way. For that, we used a web 2.0 visual tool "EdPuzzle" to show a video about bullying, having in it some questions to know if the message is delivered and understood by these students. The outcome of the study was positive and showed that the special needs students were motivated and understood the meaning of bullying from the video they saw. In addition, the students felt more comfortable and understood the lesson without asking the teacher.
\end{abstract}

Keywords:

C 2018 IJERE. All rights reserved

Bullying, web 2.0 tools, technology in education, Edpuzzle, special needs

\section{INTRODUCTION}

School years are critical for students, where they spend most of their time learning and socializing with friends and teachers. However, students at school face various peer pressure that affect their life either in positive or negative way. Bullying exists in almost all schools and it is a serious problem that teachers and administration in almost all schools, where they work to control it as much as possible within the school environment (Law son 2011).

According to Tina and Lone "School bullying is a serious problem affecting the victims" (BitschHansen and MajlundSteenberg 2012). One of the students' right that a school should provide is a safe environment, where students can learn, ask question, inquire, make mistakes, digest the information and link them to previous ones. The lack of a safe environment leads to decline academic averages. Researchers focused on bullying in the past years to study its effect on students' school life. Bennett defined bullying as something "occurring when a student is exposed to negative actions repeated and overtime by one or more students" (Bennett 2009).

Bullying considered being the most common form of violence in the society (Beane 2008). It is not a new issue; students and teachers face through time. Bullying can easily spread inside a school if adequate measures were not taken. It has negative effect on the school environment, thus affect students' life and experience during school years. It has been recorded that, bullying increases through the elementary grades and peak or become more violent in middle school (Olweus 1993). The main factors for students to bully each other is to gain power over other individuals. However, bullying is considered to be a big issue because it has negative effect on the bully, victims and the by standards. It also has long-term academic, physical and emotional consequences. Anti-bullying program has been implemented but the effective change are being relatively little or limited (Ferguson, San Miguel and Kilburn 2007).

Dealing with special needs students in a school is challenging, yet their presence in the classroom is rich as they bring different perspectives to the classroom and class discussions. How ever, the researchers noticed that special needs students have more potentials to get bullied, for that there must be an easy way to show them the meaning of bullying and to teach them the minimal of how to face them. From this idea, the researchers started this study by implementing a video that shows the meaning of bullying for gr ade two special needs students.

${ }^{1}$ Corresponding e-mail: chsemaan@hotmail.com,Lebanese University - Faculty of Education,orcid.org/0000-0003-2517-4835 
Bullying

Bullying is a major issue researches has been focusing on to study it from all perspective. Thus, this section is going to pinpoint some important points to understand the situation and act upon the data we have. Convers the definition of the bullying, different types, preventions and the technology that can be used, to help reducing its effect.

"Bullying is a repeated oppression, psychological or physical, of a less powerful person by a more powerful one" (Farrington 1993). The occurrence of bullying in a school is relatively high according to Farrington. Boys bully more than girls he added, however both boys and girls are victimized equally (Farrington 1993). Bullying is the situation where an individual bully another individual. Bully is the individual who causes the bully on other individual (Olweus 1993), while the victim is the individual who receives the negative or adverse actions in the act of bullying (Boulton and Underwood 1992). The third pillar of the bullying situation is the Bystander. A bystander is the individual who watches the bullying without being part of it (Law son, Bullying Prevention Program Design, Strategies, And Implementation In Elementary Schools 2011).

Bullying is a serious problem that attracted researchers' attention in the last decade to study it and understand it in better way. Bullying is considered a major issue and attracted school attention as most students face it during their school and professional life. The negative effect of bullying affect not only the victim, but also the bully, bystander and school environment. Moreover, we must know that According to Alannah and Madeline Foundation, there are four type of bullying, physical, verbal Social and Cyber bullying (amf.org.au 2017).

- Physical Bullying: This type of bully can include any physical contact that might or might not hurt the victim such as poking, hitting, punching or any other way. Sometimes the physical bully might be taking some of the victim belonging.

- Verbal Bullying: The verbal bully includes calling name, insult, or making a racist remark.

- Social Bullying: Considered as a silent bully as the victim might not recognize this action at first. It involves running the victim reputation behind their backs by lying and thus exclude them from the social environment they belong.

- Cyber Bullying: It can happen at any time, in public or in private and sometimes only known to the target and the person bullying." Hinduja and Patchin reported that cyberbullying affect students on behavioral and health levels, where "Both cyberbullying perpetrators and victims report negative mental health consequences, such as low er self-esteem, depressive symptoms, and suicidal ideations" (Hinduja and Patchin 2010).

Web 2.0 and technology use with special needs students

According to Oxford Dictionary, Web 2.0, or the second generation of internet has been available for everyone since early 21st century. This second generation known as social networking, and communication. The benefit of this internet generation was making the user part of a big community making intelligence cumulative by sharing and interacting (Oxford Dictionary 2017). In addition (Yuen, Yaoyuneyong and Yuen, 2011) reported positive experience and perceptions when using w eb 2.0 tools in classroom, as these tools are effective when integrated for supporting the teaching and learning process, yet the most utilized are video tools.

Teachers are using the Web2.0 tools in their lesson to reach all students in the classroom and to enrich students' knowledge on the topic covered. As some tools are various in number and function, a teacher can use different tools to assess the students' level of comprehension on the lesson. Moreover, (Hasselbring and Williams Glaser, 2000) provides an overview showing effective use of technology with special needs students can promote education level and overcome barriers and limitations to free many of them from their disabilities.

Naumes (2013) performed a study with the special needs students, indicating the effect of the visual and auditory stimuli on their attention and behavior and fostering their concentration and engagement during the task. Moreover, Aksal and Gazi (2015) stated that the integrating ICT (Information and 
Communication Technology) in special needs curriculum will help increasing students' learning efficiency and performance. Further, (Starcic and Bagon 2013) conducted a review showing results of a content analysis of all papers published from 1970 to 2011 in seven educational technology journals indexed in Web of Science, focusing on the issue that ICT supported learning for students with special needs has not received sufficient attention, where ICT can provide better education for special needs students.

Further, teachers are using the Web2.0 tools in their lesson plans to reach all students in the classroom and to enrich students' knowledge on the topic covered. As w eb tools are various in number and function, a teacher can use different tools to assess the students' level of comprehension on the lesson. Moreover, web 2.0 tools are being used with special need students and make their learning more personalized, as the tools and/or "approach will provide a long life-support learning for these students." (Semaan and Kiwan, 2017)

\section{EdPuzzle}

EdPuzzle is a web-based tool allowing teachers to pick a video for their students to watch and learn any where and any time according to their schedule and availability. This application was chosen for different reasons, mainly for its educational benefits and flexibility of the platform of this web tool. It works on Androids, IOs and web browser (edpuzzle, 2017).

The Edpuzzle help teachers providing number of videos divided into categories from different educational websites such as ted talk and khan academy. After choosing the video, teacher can choose to add audio to explain the video, comments, insights and notes. A quiz can be added on different section of the video to assess students' understanding and knowledge (edpuzzle 2017). Moreover, (Eng, 2017) elaborated teachers need to follow the students' needs in education, where learners love watching videos. Adding on, Edpuzzle allows embedding questions inside a video that makes it an amazing tool for students as they can interact with the video while watching.

\section{RESEARCH METHODOLOGY}

Sample:

To test the effect of the Edpuzzle on decreasing the bullying inside the school environment specially by raising aw areness on the targeted audience, the researchers picked a second grades special need students to implement this study. It w as noticed that as from this early age, students are starting to bully each other. For this, second graders were picked to be the class understudy. This classroom has 10 special needs students. The cases in the classroom are classified as: Autism spectrum disorder, learning disabilities/difficulties.

Context of the study and participants:

The researchers has chosen the selective purposive sample. In the study, we focused on 10 candidates from the Grade two small group class with specific characteristics (special needs), in the same age range (6-8 years old) to work with for many reasons. They have ASD (Autism Spectrum Disorder), ADD (Attention Deficit Disorder) or ADHD (Attention Deficit and Hyperactivity Disorder) and the teacher find that introducing a new concept a challenging matter which will take time and effort to find a way that they can reach these students.

Reasons why the researchers chose this class are that the teachers face many challenges to clarify and introduce new lessons and subjects to special needs students. Moreover, the students need modifications and adaptations in order to grasp the lesson's objectives and increase their level of performance as they have difficulties acquiring new concepts.

Variables

Independent variables: EdPuzzle.

Dependent variables: Level of knowledge and acquisitions, Students' behavior, Concentration.

Instruments: 
- The researcher used teacher's pre and post interviews, as well the student's observation while w orking, to observe many variables, concentration, engagement and lesson comprehension.

- The Edpuzzle data section to collect the student's result.

Procedure

The procedure of the study was divided into several steps, where the first step was interview ing teachers and choosing the class. While the second step was creating Edpuzzle accounts for the students and demonstrating its features.

Data collection and analysis

The third step took place after choosing the sample and getting the principal's approval. The study's procedure implemented with many plans of action: interview done with teacher; also, phone interviews held with the parents. Later on, a training session was held with the homeroom teacher to demonstrate the features of Edpuzzle.

After creating the account for the students where each had a username, we chose the lesson in social studies, with a subject about bullying to make the special needs students understand more about this topic. Then, the teacher used a 4:06 minutes video from YouTube ab out bullying appropriate for their age, adding five multiple-choice' questions, also inserting voice notes into the questions for the students to be able to read and hear, which will improve the question comprehension. This took place after doing a pre int erview about Edpuzzle and the researchers taught the teacher and her assistant how to use Edpuzzle. Then, the computer laboratory was booked to complete the sessions on two steps, dividing the class into two separate groups with different schedules, in order to be able to help them during the lesson if needed.

The session took place in the computer lab, where the students started the session after logging into their accounts. They were cooperative and seemed excited discovering a new game. In the students' thoughts, the computer lab is a place where they can have fun. Thus, they were motivated to start the task, and following all instructions given from the teacher. Afterwards, the students had the chance to watch the video more than one time and thus had the chance to correct their answers when it needed. Their selfconfidence notably increased as it showed with less help-request from the teachers' assistant.

Post interviews with the homeroom teacher and her assistant were done when the Edpuzzle lesson is completed, to share their feedbacks and suggestions for future sessions. Later on, the researcher gathered the interviews and collected the data from Edpuzzle to analyze them.

We all know that parents play a major role in the personal and educational life of their child, as their involvement will play a significant role in supporting their academic performance (Okten, 2016). For that, the researchers with the help of the teacher sent with students his/her username and password as a home exercise in order to repeat it with their parents and explain what they learned from the video. Later, a phone interview took place with the parents to take their feedback.

\section{DISCUSSION AND FINDINGS}

Impact on students:

These students were engaged in doing the multiple types of activities. Moreover, they were very happy and enthusiastic achieving such task independently with minimum help from the teacher, also noticed an increase in their level of performance as the results in Edpuzzle revealed (Stefania Pinnelli et al., 2016). They were more concentrated and enjoying visualizing the concept. Edpuzzle allows the student to repeat the question more than one time, and repeat the video at the end, which the students will feel more comfortable to understand the lesson without asking the teacher. After practicing the Edpuzzle video exercise and answering to the relevant questions, the students understood the meaning of bullying. The use of ICT has shaped the knowledge and the skills of teachers, therapist, and special educators, which helped them to implement technological strategies of learning to help each student to overcome his difficulties in learning by pointing out the needs of each individual (Drigas and Ioannidou, 2013).

(Acedo, 2013) conducted that Edpuzzle will encourage the students to practice more than one time the new concept. These students were highly motivated to complete the activity independently without the 
teacher's help. They grasp the meaning of bullying in an easy and interactive method. Thus, their selfindependency will increase at school and home along with motivation and engagement in such task. Furthermore, the researchers accomplished the purpose of the study, which was, the researchers saw that special needs students have more potentials to be bullied, for that using Edpuzzle video about bullying an easy way to show them the meaning of bullying, but we need another videos to teach them the minimal of how to face them.

Impact on teachers and feedback:

Edpuzzle has many benefits on teachers, as it decreases the time of lesson's preparation as they can share their activities with other teachers. Moreover, the class level of performance will rise (Lewis James, 2013). Additionally, the worksheet time correction will decrease, where the outcome of the activity can be printed easily after each activity. Furthermore, the increasing in teacher's experience using technological tools will be noticed and will enhance the quality od education affecting the school system in general (Walsh, 2012).

No behavior challenges shown during the entire lesson, which was a breakthrough for this class, especially that all teachers was facing behavioral problems with these students, whenever they were introducing a new lesson and concept. Being able to catch up with missed content, will enhance the student comprehension and will improve their self-confidence and improves achievement (Noonoo, 2012).

Outcome of the parents' phone interview:

The parents found Edpuzzle is the perfect educational learning game for their children as they revealed in the phone interview. Where one parents said the child is a visual learner and was learning another language from YouTube videos, thus Edpuzzle was reinforcing the learner to acquire the concept of bullying. Other parents noticed the time acquiring the bullying lesson with the visual support using such tool $w$ as remarkable. In addition, the parents found grounds for hope in Edpuzzle to increase their children performance and they wished to be implemented in other lessons to support the learning process to suit their children level of acquisition.

\section{CONCLUSION}

After showing to the special needs students a video using Edpuzzle tool about bullying. These students had to answer several questions about this topic while watching, which helped in delivering the message and understanding the meaning of bullying, knowing that ICT use with special needs can make their leaning more personalized, and the tools used will provide a long life-support learning.

How ever, one video helped us delivering and elaborating the meaning of bullying, and we could see its effect from the student's actions, teacher's point of view and the parents' reactions. Hoping that, later on, we could go deeper into the subject with these students by applying more videos using Edpuzzle in the future about bullying, as they should watch and learn from videos about different kinds of bullying, as how to solve these kinds of disputes. Furthermore, we should get to a point with these special needs students where they can face bullying matters on their own when they encounter it.

\section{REFERENCES}

Abou Afach, S., and Kibbi, I. (2016). The Role of the Flipped Classroom to Enhance User Experience in Cells and Molecules Course Junior-Leveled Students. IJIRES, 3.3, 198-207.

Acedo, M. (2013, novembre 27). 10 Pros And Cons Of A Flipped Classroom. Consulté 20 novembre 2017, à l'adresse https://ww w.teachthought.com/learning/10-pros-cons-flipped-classroom/

Amf.org.au. (2017). Retrieved october 2017, from https://www.amf.org.au/bullying-advice/bullying-forparents/types-of-bullying/

Aksal, F. A., and Gazi, Z. A. (2015). Examination on ICT Integration into Special Education Schools for Developing Countries. Turkish Online Journal of Educational Technology - TOJET, 14(3), 70-72. 
Beane, A. (2008). Protect Your Child from Bullying, Expert Advice to Help You Recognize, Prevent, and Stop Bullying Before Your Child Gets Hurt. A Wiley Imprint.

Bennett, c. (2009). Literature Review of Bullying at schools.

BitschHansen, T., and MajlundSteenberg, L. (2012). A review of psychological factors related to bullying victimization in schools. 17(4), 383-387.

Boulton, M., and Underwood, K. (1992). Bully victim problems among middle school childr en. Journal of Educational Psychology, 62, 73-87.

Drigas, A., and Ioannidou, R. E. (2013). Special Education and ICTs. International Journal of Emerging Technologies in Learning (iJET), 8(2). https://doi.org/10.3991/ijet.v8i2.2514

Edpuzzle. (2017). Retrieved 10 23, 2017, from https://edpuzzle.com/classes

Eng, Norman. 2017. "5 Tech Tools Every Professor Should Use Now." http://academicw orks.cuny.edu/cc_pubs.

Farrington, D. (1993). Understanding and Preventing Bullying. . Crime and Justice, 381-458.

Ferguson, C., San Miguel, C., and Kilburn, J. (2007). The Effectivness of School-based Anti Bullying Programs.

Hasselbring, Ted, and Candyce Williams Glaser. (2000). "Use of Computer Technology to Help Students with Special Needs." The Future of Children CHILDREN AND COMPUTER TECHNOLOGY 10 (2): 102 .

Hinduja, S., and Patchin, J. (2010). Bullying, Cyberbullying, and Suicide. (D. 10.1080/13811118.2010.494133., Ed.) Archives of Suicide Research, 14, 206-210.

Lawson, J. (2011). Bullying Prevention Program Design, Strategies, And Implementation In Elementary Schools.

Lewis James. (2013, juin). T216 Best of Computer in Education Division: American Society for Engineering Education. Consulté $20 \quad$ novembre 2017, à l'adresse https://www .asee.org/public/conferences/20/registration/view_session?session_id=2008

Naumes, J. (2013). Use of Technology in Occupational Therapy Rehabilitation from an Elderly Perspective. Interface: The Journal of Education, Community and Values, 13. Consulté à l'adresse http://commons.pacificu.edu/inter13/17

Noonoo, B. S. (2012, juin 20). Flipped Learning Founders Set the Record Straight -. Consulté 20 novembre 2017, à l'adresse https://thejournal.com/articles/2012/06/20/flipped-learning-founders-q-anda.aspx

Okten, P. (2016). Parental Academic Support in Education. International Journal of Educational Research Review 1 (2): 18-24.

Olweus, D. (1993). Bullying at School: What we know and what we can do. Cambridge, Massachusetts: Blackwell Publishers.

Oxford Dictionary. (2017). Retrieved 2017,from https://en.oxforddictionaries.com/definition/web_2.0

Semaan, C. and Kiwan, E. (2017). Impact of "kubbu" on the Academic Achievement and Motivation of 4 th Grade Special Needs Students. International JOurnal of Innovation and Research in Educational Sciences 4 (6): 683-689. 
Starcic, Andreja Istenic, and Spela Bagon. 2013. "ICT-supported learning for inclusion of people with special needs: Review of seven educational technology journals, 1970-2011."

Stefania Pinnelli, Fiorucci Andrea, and Clarissa Sorrentino. (2016). Flipped Classroom and University: the TicandDIL Project and Students' Perceptions. International Journal of Learning and Teaching, 2(No. 2).

Walsh, K. (2012, mai 8). 8 Great Reasons to Flip Your Classroom (and 4 of the Wrong Reasons), from Bergmann and Sams I Emerging Education Technologies. Consulté 20 novembre 2017, à l'adresse http://www.emergingedtech.com/2012/08/8-great-reasons-to-flip-your-classroom-and-4-of-the-w rongreasons-from-bergmann-and-sams/

Yuen, Steve, Gallayanee Yaoyuneyong, and Patrivan Yuen. (2011) "Perceptions, Interest, and Use: Teachers and Web 2.0 Tools in Education." International Journal of Technology in Teaching and Learning 7 (2): $109-123$

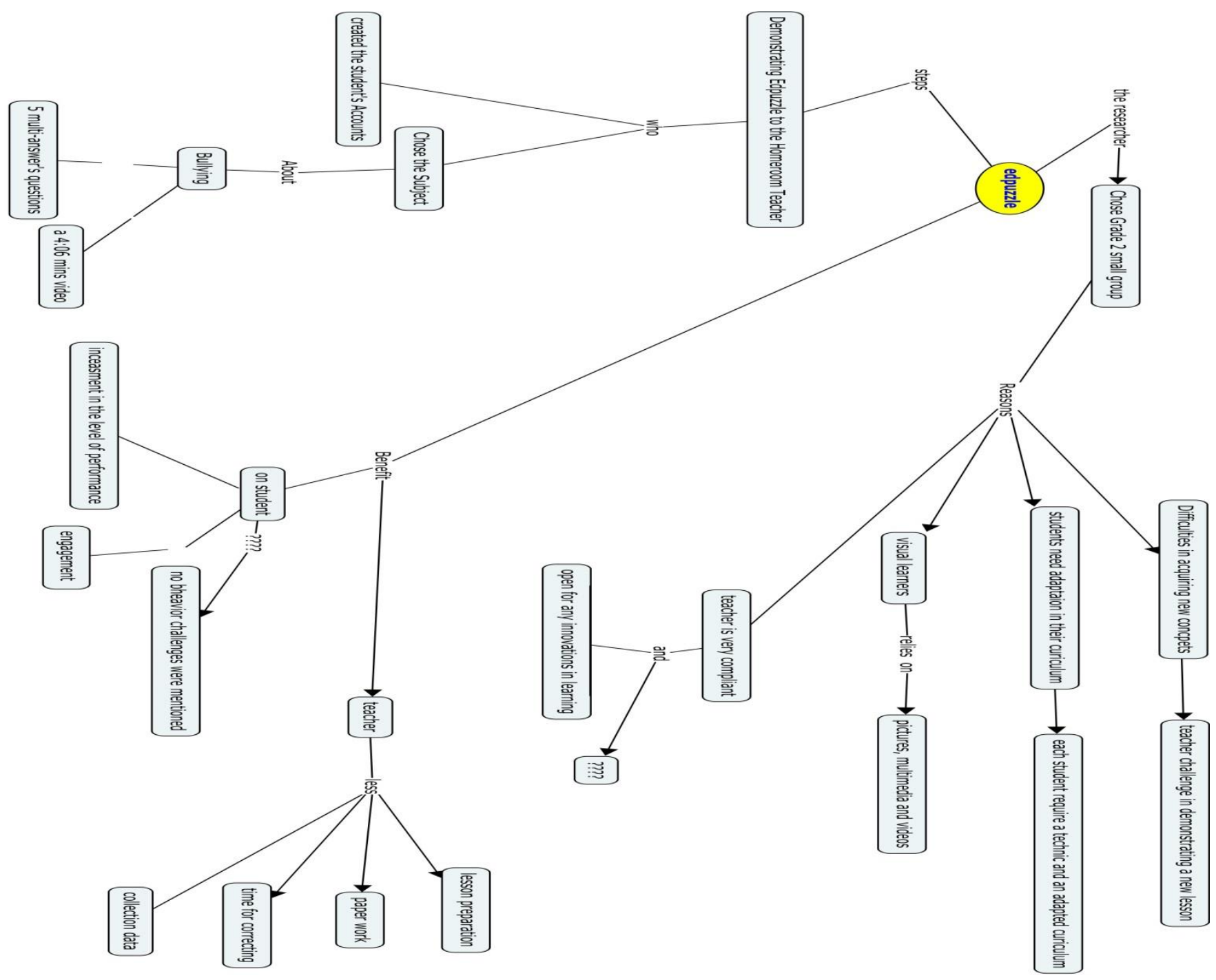

